Article

\title{
Contemporary Misticism: Recovering Sensible Aesthetics in an Age of Digital Production
}

\author{
Randall K. Van Schepen
}

School of Architecture, Art and Historic Preservation, Roger Williams University, One Old Ferry Road, Bristol, RI 02809, USA; rvanschepen@rwu.edu

Received: 28 January 2019; Accepted: 6 March 2019; Published: 12 March 2019

check for updates

\begin{abstract}
Materialist accounts of artistic development emphasize the ongoing revolution of media in the progress of history. Amongst the most popular accounts of modernity are Walter Benjamin's essays on the relationship of photography to traditional art. His account of the loss of aura has been subject to countless reinterpretations since its publication. The present essay addresses the contemporary production of a number of architects and artists whose work provides an interesting challenge to the Benjaminian account of the secularization of artistic ritual. The artists Adam Fuss, Vera Lutter, Alison Rossiter, Sally Mann, and others have recently been exploring photographic methods that contradict the Benjaminian account of the history of photography. They continue to explore techniques that Benjamin placed in the auratic pre-paper-print era, such as Daguerreotypes and photograms, as well as employing other more material/chemically based effects. Such artistic choices are often considered nothing more than a nostalgic reverie trying to stem the tide of materialist history, a flawed search for a lost aura of presence. However, when these works are set against the backdrop of contemporary digitized production and of the Dusseldorf School as well as most other contemporary photographers, these "retro" works stand as a critical counterpoint to our present seamless digital imperium. The soft and hazy effects of these works, what I am calling their misticism, occludes the particularity of digital bits of information in a search to connect to the material and the sensual, something denied by information-saturated technologies. Even within a materialist approach to history, there is room to view these architectural and artistic effects as critically productive rather than merely retrograde. The present essay argues for the timely relevance of contemporary retro-photographic techniques in fostering both a critical attitude and as evidence of attempts to recover a sense of spiritual presence.
\end{abstract}

Keywords: aura; retro-avant-garde; aesthetics; mysticism; digital imagery; photography

Wilson: "But what shall we dream of when everything becomes visible?"

Virilio: "We will dream of being blind."

Paul Virilio, $1994^{1}$

\section{Introduction: The Digital Imperium and Mistical Artists}

Marching to an unknown future, present technologies of image production and consumption ceaselessly advance to ever greater levels of visual acuity. The digitized realm of experience we now float in has only made the striving for atomized clarity more obvious and more subject to the demands

1 Paul Virilio in Louise Wilson's interview (Wilson and Virilio 1994), “Cyberwar, God and Television: Interview with Paul Virilio." on CTheory.org, published 1 December 1994; accessed 1 December 2018 at http:/ / www.ctheory.net/articles.aspx? id $=62$. 
of an insatiable audience, on the one hand, and to the corporate and administrative purposes who control its flow. Considered merely as a digital version of the historical string of ever-improving image-making technologies since the advent of photography, such restless strivings could be correctly understood as merely the latest manifestation of a pathetic, mindless, and reflexive industrial impulse beating at the heart of modernity-a desire to protect market share by constantly repopulating the commercial sphere with improved products that make last year's technologies at the very least unfashionable, if not functionally obsolete. It seems, however, that there is more at stake in our embrace of this endless, visually stupefying digital "progress" than such a structural economic analysis might reveal. The present essay suggests that such hyper-real digital imagery colonizes the material reality it points to, transforming our experience of materiality into one that is increasingly abstracted from the body. In response to this culturally dominant impulse, it suggests that certain architects and artists "mistify" images by occluding them in order to recover a more immediate and sensuous relation to the world, one that nevertheless also ushers in the spiritual. ${ }^{2}$

Carried along by this wave of innovation and digitized evolution, our consumerist environment is saturated with image-making and image-circulating modes of aesthetic production. The artworld is not immune to these larger tendencies. There is ample evidence of artists working in modes that take advantage of the qualities foregrounded in digitized production, whether through photography, video, virtual reality or other digitally immersive media. As Paul Virilio noted some two decades ago, "We cannot help but notice today the decline of ... analogue mental processes, in favor of instrumental, digital procedures ..." " alienating us from the world to which it refers, a process which he traces back to Walter Benjamin's comments on print photography as "opening a field in which all intimacy yields to the illumination of detail. ${ }^{3}$ This striking incompatibility between obsessive details and intimacy is explored here in relation to a sampling of recent works of art and architecture, whose ambiguous and indistinct character seems a conscious antithetical foil for the dominant desire for greater digitized clarity. The choice of such archaic imagery or techniques, leading to more ambiguous experiences, seems to invite an analysis of the metaphysical implications of such effects rather than a simple accounting for their merely sensually evocative character. The larger social context, of the seemingly inevitable subsumption of reality by the digital or the virtual will hover over this discussion much as the digital "cloud" hover over, above and beyond our direct experience or control. The implication of such artistic choices is that they come with metaphysical as well as sensual implications. Virilio suggests that the "endocolonization" of our lives by digital recording devices has the potential to lead to a "world without intimacy" - a "world which has become alien and obscene, entirely given over to information technologies and the over-exposure of detail." 4 In fact, Virilio argues that the level of this digital virtuality is so pronounced that is goes well beyond Jean Baudrillard's notion of simulation into a state of substitution. In Virilio's state of substitution, the digital realm is so powerful and prevalent as to be independent of the "original" reality to which it once might have referred. Thus, two realities exist instead of a singular reality to which the (digital) signifier points. ${ }^{5}$

Against this endocolonization, or at least in response to it, the artists and architects discussed here produce effects contrary to those typical of digitized bytes of visual information. The danger of the purely visual and wholly digitized data-body, Vivian Sobchack argues, is in its "devaluing [of] the physically lived body and the concrete materiality of the world" to the point that this "dominant cultural and techno-logic informing our contemporary electronic 'presence'" runs the risk of making

2 The present study is related to similar research on affective, sensory, and bodily responses in aesthetic and political theory. For a summary of these haptic approaches in relation to architecture, see (Paterson 2016). His survey of the literature is oriented around movement in architectural experience more than bodily presence, but they are clearly related responses to a static vision organizing visual information.

3 (Virilio [1998] 2000, p. 2). Virilio is referring to Benjamin's 1936 essay on mechanical reproduction (Benjamin [1936] 1992). (Virilio [1998] 2000, p. 57).

(Wilson and Virilio 1994, interview). 
us "merely ghosts in the machine". ${ }^{6}$ The photographers Adam Fuss, Vera Lutter, Sally Mann, and Alison Rossiter and the sculptor Olafur Eliasson and architects Diller + Scofidio variously blur, occlude or obscure visual detail or information using mist, smoky, hazy or out-of-focus effects. This list is only a sampling of artists whose work employs occluded imagery or ambiguously articulated space. Others might include Gerhard Richter (photopaintings), Paul Graham (American Night series 2010-11), and Nina Canell's Perpetuum Mobile (2009-2010), to name a few. Because the techniques these artists and architects employ vary from the antique to the highly technological, this essay is not a diatribe against all things digital - although it must be said that the inherent strengths of a medium come into play as tendencies in production and reception. There is no avoiding the fact that the differences between digital and analogue photography, for example, are of such a magnitude that they press towards the likelihood of certain artistic choices being made, such as highly saturated color and obsessively plotted detail and resolution.

\section{Mistical and Mystical}

A final introductory note on the word "mysticism" versus my use of the term misticism in defining this creative strategy. The use of misticism firstly relates to the blurry and cloudy visual effect of these artists and architects. The fact that I have chosen architects and photographers as my main examples is also intentional, as both of these fields of cultural production foreground relations to the material world in a way that painting does not. When employing "misty" effects, they thus provide particularly problematic but also interesting test cases for the aesthetic under discussion. The major secondary association for the term misticism is, of course, in relation to theological "mysticism". Mysticism's association with via negativa is perhaps the most pregnant association for these mistical artists, as it is through the lack of information, the negated status of the image, that one comes to know the nature of the subject. This dialectical inversion of materiality into spiritual effect, of lack of information into presence, is the operational nature of these evocative rather than descriptive mistical works. The first thorough discussion of the cloudlike architecture of Diller + Scofidio's Blur Building in relation to The Cloud of Knowing is by Jeffrey Kosky. ${ }^{7}$ In a very convincing and compelling analysis to which I am indebted, Kosky discusses a few contemporary artists who explore spiritual themes in their work. In a more aesthetically particular fashion, the present essay proposes that mistical effects are particularly effective at evoking the contemporary spiritual experience; ironically, they do so through a greater attention to bodily experience.

\section{Mistical Spatial Articulation}

Because the issues of spatial articulation are distinct from two-dimensional representation, initially I would like to introduce two sculptors and architects dealing with misty/foggy spatial articulations. Olafur Eliasson has worked on this kind of color- and mist-saturated space since the mid-2000s, with at least one of these works being constructed in collaboration with an architect. In 2003, Eliasson was chosen as the artist to take over the Turbine Hall of the Tate Modern, installing one of the most successful interventions in that series, Weather Project. 2009 and 2010 were especially productive years continuing this vein of exploration, with works such as Your Atmospheric Colour Atlas (2009) and Feelings

6 Vivian Sobchack's idea of an ethical cinema that engages the "haptic" body can be found in her (2004) Carnal Thoughts: Embodiment and Moving Image Culture. (Sobchack 2004, p. 162). See also Laura U. Marks's notion of the (implied) element of touch in moving images, in (Marks 2008, pp. 399-407). Noting that film and video "become more haptic as they die", caused by scratches, fading and deterioration, Marks clarifies that her "definition of visual tactility, however, has little to do with physical texture and mainly to do with the way the eye is compelled to 'touch' an object... The techniques ... do not necessarily make a film look tactile. However, optical printing can build up many layers of images on the film, producing a thicket of barely legible images" (p. 401). With obvious similarities to the artists and architects discussed here, she notes that filmic "graininess certainly produces a tactile quality, as the eye may choose between concentrating on figures and ignoring the points that make them up or bracketing the figures and dissolving among the points" (p. 402). Marks's theories are more fully developed in her The Skin of the Film: Intercultural Cinema, Embodiment, and the Senses (Marks 2000).

7 (Kosky 2013). 
Are Facts (2010), Your Blind Movement (2010), and Your Blind Passenger (2010) employing colored lights and a fog machine to create a highly saturated and indistinct spatial experience. Even in 2016, Eliasson produced Fog Assembly as a part of his intervention at the palace of Versailles. In addition to Eliasson's gallery interventions, an interesting and highly technical example of the construction of mistical space in architecture can be found in Diller + Scofidio's Blur Building, which was built for the Swiss Expo at Lake Neuchatel in 2002.

Eliasson's Weather Project, an immense warm-toned light installation in that vast hall, brought sun to London, hence its popularity. It was composed of a semicircular screen that radiated solar-colored light, a ceiling that was mirrored to encourage self-reflection and communal posing, and a gallery whose air was diffused with an artificially produced mist. Laying prostrate on the floor, lounging with one another, Londoners found the installation not only immensely rewarding physiologically, but also socially, as this gathering space fostered the organization of spontaneous social units, often made of participant bodies posing in shapes or words (a peace sign, the words, "Bush Go Home," etc.). Extending this popular if not critical success, Eliasson worked on a series of similarly atmospheric light installations in 2009-2010, beginning with Your Atmospheric Colour Atlas, which employed artificially produced fog infused with red, green and blue colored light (the additive colors of RGB) from a grid of fluorescent fixtures installed on the ceiling. Visually navigating these works became increasingly complicated as later pieces, such as Feelings are Facts with architect Ma Yansong, which was installed in the Ullens Center for Contemporary Art in 2010, changed the pitch of the floor from one end of the gallery to another along with dropping in the height of the ceiling grid. Participants therefore had to give up visually dominated navigation in order to adapt to this constantly changing spatial environment.

In each installation of 2009/2010, but especially with Feelings are Facts, viewers had to "constantly renegotiate their balance by shifting their weight and posture-with only the fields of colour to guide them intuitively through the dense atmosphere." ${ }^{8}$ In the lack of distinction between participant and work, body and color, mist and solids, Eliasson's mistical works encourage a bodily processing of information in a way which is sympathetic to a phenomenological mode of understanding. Merleau-Ponty's notion of space as co-existent with the body rather than objectively separate from it (filling it as spatialized or spatializing rather than a mutually dependent relation) develops into a chiasmic sense of the exchange possible between the body and things. Choi (2014) has fruitfully introduced Elizabeth Stöker's notion of "attuned space" into his discussion of Eliasson. Eliasson's ambiguous spatial articulations seem to illustrate Stöker's attuned space as "not primarily an object for a subject who performs acts of spatial understanding. Rather, as attuned space, it has an appropriate mode of coexistence with the corporeal subject." ${ }^{\prime 9}$

There is an open question as to whether Eliasson's work participates in the construction of a society of spectacle. Spectacle, the definition of which has not achieved critical consensus, resides at the intersection of late capitalist corporate branding, seductive aesthetics, and an uncritically immersive experience. ${ }^{10}$ It is against the sheen of seamless, highly produced, enticing aesthetic pabulum that contemporary critical artistic practice is set. Boris Groys, for example, suggests that "art must be directed against contemplation, against spectatorship, against passivity of the masses paralyzed by the spectacle of modern life." ${ }^{\prime 11}$ While Eliasson's work has sometimes been critiqued as participating in the production of Debordian spectacles, these works construct experiences that are slow, meditative, and draw out sensual content not easily conformed to spectacle's purposes. Eliasson and the other artists

8 Eliasson's studio's official website, https:/ / olafureliasson.net/archive/artwork/WEK100050/feelings-are-facts (accessed on 12 December 2018).

9 (Elizabeth 1965, p. 20).

10 See Claire Bishop's critique of participatory practices, "Participation and Spectacle: Where Are We Now?" in (Thompson 2012, pp. 34-45). See pages 35-36 for her discussion of "spectacle."

11 Groys in Bishop, p. 36; from Boris Groys, "Comrades of Time," e-Flux Journal, 11 December 2009, available at www.e-flux. com. 
under discussion here employ effects that encourage what Renee van de Wall calls "tasten denken" in Dutch, or a groping form of thinking through the senses. ${ }^{12}$

Diller and Scofidio claim that the indistinct character of Blur Building (2002) and the viewer's inability to construct a coherent whole while experiencing it creates an environment that counteracts the contemporary desire for slickly-packaged and branded spectacle, even suggesting that it should be understood as "anti-spectacle". Blur Building's mist-saturated, ambiguously articulated space shares a visual syntax of vague form, palpable atmosphere, and quieting softness with Eliasson's Weather Project and other foggy projects. Blur Building's 90 by $70 \mathrm{~m}$ cage-like structure of pipes was suspended on a platform above Lake Neuchatel and emitted fine particles of water that created a cloud. This mist-cloud hovered above the water, enveloping the frame and participants, questioning the very nature of architectural enclosure-spatial enclosure being one of architecture's supposedly essential qualities. Figures walking through the mist visually appear and disappear, hovering on the edge of a felt rather than optically plotted presence. As Diller + Scofidio describe it:

Upon entering the fog mass, visual and acoustic references are erased, leaving only an optical "white-out" and the "white-noise" of pulsing nozzles. Blur is an anti-spectacle. Contrary to immersive environments that strive for high-definition visual fidelity with ever-greater technical virtuosity, Blur is decidedly low-definition: there is nothing to see but our dependence on vision itself. ${ }^{13}$

Participants struggling with basic ocular recognition were given "brain coats" which were programmed with their personal preferences and which would light up when in the proximity of someone with similar tastes. Blur Building, like the Relational Aesthetics to which it is indebted, attempts to overcome the isolation of our postmodern age of information overload by fostering the emergence of a new sensus communis, but one that nevertheless acknowledges our present distance from each other. ${ }^{14}$

One of the most astute analyses of Blur Building was undertaken by Jeffery Kosky in Arts of Wonder: Enchanting Secularity —Walter DeMaria, Diller + Scofidio, James Turrell, Andy Goldsworthy (2013), a work that the present discussion has great sympathy with. Embracing Ashley Schafer's notion of "inefficient technologies," Kosky contrasts the Cartesian notion of illuminating things clearly and distinctly so that they are available for our rational mastery to Diller + Scofidio's project which is consciously designed to obfuscate any readily available rational understanding through its shrouded, cloaked, and ever-variable form. ${ }^{15}$ Made in 2002, when the idea of the computational digital cloud was in its infancy, Blur Building nevertheless speaks to the contemporary, ambiguously formed digital identities we have floating in the cloud as well as the digital communities that are formed as a result. At the same time, the direct spatial experience forces an improvisational and intuitive response to its constant sensual reconfiguration, one that is subject to wind, light, participants, and unknown variables that "do not offer ultimate security, certainty or control". ${ }^{16}$

12 (van de Wall 2008, p. 5): “'Tastend denken' then might describe a kind of thinking that is modelled upon the sense of touch as it is usually conceived: a thinking that has to make do without the overview accorded to sight, fragmentary and uncertain about its direction, but in close contact with what it thinks about and even assuming the form of what it holds."

13 Diller + Scofidio on their website, accessed, 18 May 2011: http://www.dillerscofidio.com/blur.html. YouTube Video: http: / / www.youtube.com/watch?v=0WT5Lu1MKYs\&feature=player_embedded\#at=220.If out-of-focus-ness and blurriness are relatively common in works of two-dimensional art, they are decidedly not readily employed in the realm of architecture. Diller, Scofidio + Renfro have since changed their website and this quote is no longer a part of their description therein: https: / / dsrny.com/project/blur-building (accessed on 1 March 2019).

14 The original formulation of "relational aesthetics" was introduced in 1998 by is Nicholas Bourriaud in Relational Aesthetics, les presses du réel: Dijon, 1998/2002.

15 (Kosky 2013, pp. 69, 84).

16 (Kosky 2013, p. 176). 


\section{Photography's Technological Burden}

The creative fascination with clouds, blur, mist, fog, and other occluding visual effects is not limited to sculpture and architecture. If anything, drawing, painting, and photography are more likely to manifest these characteristics than the three-dimensional arts (which have to undertake heroic, often highly technical, efforts to mistify their forms). The shift from three- to two-dimensional imagery also requires a conceptual reorientation because not all two-dimensional media have an equally conflicted relationship between clarity and cloudiness, resolution and refraction, or definition and diffuseness. In the hands of the great Romantic painters, such as Caspar David Friedrich, the representation of mist is a way to evoke, among other things, the divine mysteries of nature. In drawing, the subtle, shrouded, tonal ranges of a George Seurat or Käthe Kollwitz's charcoal show the figure's gradual emergence out of a range of gray and black, without the defining linear marks that make up more typically defined drafted forms. In these cases, the blurriness of forms is not considered a compromise or denial of information but an embrace of the positive effects of fog or tonal subtlety. The painter Gerhard Richter discusses the "blurriness" of his out-of-focus photopaintings as a positive effect rather than a deficient image missing information. He defiantly claims that one cannot blur a painting, only a photograph. It is the presumed coherence and clarity of the photographic source image that is undermined by the haziness of its resolution. Ironically, Richter's claim notwithstanding, I would argue that this is the very reason why Richter's photopaintings can legitimately be called blurred. It is because Richter's photopaintings inherit the mantle of the presumed photographic clarity and indexicality of their source while denying it in paint. That is, we know that while Richter's source images were originally focused and that they also had a direct correspondence to the material reality that they representationally point to, he then proceeds to artistically destroy this relationship by occluding the image with his painterly effects. Other than examples such as Richter's photographically derived paintings, however, it is in contemporary photography more so than painting that one finds a strategic embrace of the veiled imagery characterized above as contemporary misticism. However, most photographic production proceeds in lockstep with the impulses that determine our present technological digital imperium.

The Dusseldorf School (Andreas Gursky, Thomas Struth, Candida Höfer, Thomas Ruff, etc.) represent an approach to photography that has led to large-scale, digitally produced, informational-laden images flooding into contemporary galleries. Following on the heels of their more conceptually oriented teachers, Bernd and Hilla Becher, Dusseldorf school photographers adapted their anonymous, factual images to the newly available digital technologies, increasing the size, resolution, and intensity of color of the Becher's multiple-image Typologies series. However, instead of a wry wit employed in the chronicling of vernacular architectural forms, Dusseldorf photographers chose highly saturated spectacular images that impress with a massive display of discrete bits of visual data. Although Dusseldorf School photographs and the images of those who follow them exist at such a scale as to dwarf the viewer, virtually enveloping them, the feeling is less of a sensual surrounding than of an undifferentiated field of discrete bits of information, information for the eye rather than experience available for the body.

This pursuit of a more seeming fidelity in the "big digital photograph" directly mirrors the same trajectory of consumer image-technologies, from VHS to DVD to Blu-ray to HiDef to 4K to VR. The relentless megapixel race is currently running up against our ability to even discern differences between $1080 / \mathrm{HD}, 2 \mathrm{~K}, 4 \mathrm{~K} / \mathrm{UltraHD}, 8 \mathrm{~K}$, etc. These resolutions present images so vibrant that they promise to sate our desire to see imagery at a level of definition that rivals or even supersedes that of life. As participatory practices in performance art seek direct contact with the audience/participant, consumers are simultaneously being enveloped in and shaped by the virtual spaces we navigate between on the screens distributed throughout our daily existence: From tablet, to computer, to projector, to TV.

Ironically, as screens increase in size and are more fluidly integrated throughout life, continually pulling us into the vortex of isolated digital experience, we are abdicating the social and political sphere in which avant-garde practice is supposed to operate. How is it that we can recover a sense 
of the body in this datascape? Vivian Sobchack suggests that a sense of embodiment is necessary to counteract, or to simply act, in the face of the constant digitization of life. Ethical recovery is discovered through the body, where "the lived sense and feeling of the human body [is] not merely as a material object one possesses and analyses among other objects but as a material subject that experiences and feels its own subjectivity."17 Thus, even though artistic production should be in step with technological progress, technology should provide an opportunity to recover our ethical bodily presence and not merely reiterate the cultural logic that produced the technology. As Adorno warns, "the growing relevance of technology in artworks must not become a motive for subordinating them to that type of reason that produced technology and finds its continuation in it." 18

\section{Mistical Contemporary Photography}

It is against the contemporary atmosphere of the reigning digital imperium—further enabled, I would suggest, by the work of many contemporary digital photographers-that the "retro" effects or techniques of Fuss, Derges, and even Ruff is best understood. Instead of a mere romanticizing of contemporary life, the ambiguously misty and occluded forms they construct can be understood as attempts to reengage the contemporary body with materiality. Rexer's term, the "antiquarian-avant-garde", 19 is appropriate for artists such as Sally Mann, Fuss, and Derges who employ 19th-century photographic techniques such as photograms and Daguerreotypes to produce some of their imagery. However, ambiguous images that call forth a more embodied form of consumption can also be produced by more technological means, such as those found in the work of Thomas Ruff or Alison Rossiter, both of which harness media to evoke qualities lost in the transition to the digital universe. ${ }^{20}$

When contemporary retro-avant-garde photographers such as Fuss or Derges employ historic, often camera-less, 19th-century techniques in a "straight" form, the resulting images are often less visually defined than traditionally printed images, or especially those of digital processing. ${ }^{21}$ The work of Adam Fuss (1961-)employs two primary historical techniques, daguerreotypes and camera-less photograms. These result in images that are often not much more than silhouettes. However, the limitations of detail in Fuss's work bring forward other sensual effects in experience, not the least of which is the strong indexical and bodily relationship between image and its source. The bodies so portrayed are not isolated from their environments but imbricated in a field of energy or light, where physical presence and our sensual reception of the image brings out haptic rather than purely optical effects.

In Love (1992), Fuss placed two dead rabbits with their entrails on the surface of color photographic paper to make a direct impression of their jewel-like, almost floral character in a photogram silver dye bleach print. A 2015 photogram, Self Portrait, created a life-sized image of the artist, floating in a

17 (Sobchack 2004, p. 178).

18 (Adorno 1997, p. 264).

19 (Rexer 2002).

20 Historically, it is certainly the case that there is a small subset of photographers who have always emphasized the ambiguous image. Many of them, such as Oscar Reijlander, Gertrude Käsebier, or Edward Weston, intentionally contradict the more typical ceaseless search for visual acuity with consciously courted arty or abstract effects. The presence of a small number of these exceptional photographers only serves to prove the rule of the photograph's default pursuit of "veracity".

21 A list of contemporary artists who use analog versions of historic techniques, such as daguerreotypes, photograms, wet-plate collodion, and tintypes would be too extensive to be comprehensively accounted for here, but Sally Mann, Jane Hinds Bidaut, Chuck Close, Luis Gonzales Palma, Takashi Arai, Matthias Olmeta, Floris Neusüss, Vera Lutter, Craig Tuffin, and Kasia Wozniak are just a few representative early-21st century artists creatively employing early-19th-century media. There have been a number of recent surveys of this phenomenon: USC Fisher Gallery, "Lost and Found: Rediscovering Early Photographic Processes" (2001); Rexer's Photography's Antiquarian Avant-Garde (2002); The Victoria \& Albert Museum, "Shadow Catchers" (2010); and Howard Greenberg Gallery, "A New and Mysterious Art: Ancient Photographic Methods in Contemporary Art" (2016). 
pool of water, lit from above, producing a fluid silhouette. Fuss's approach, in which there is often physical contact between the subject and the surface on which the image is made, foregrounds what Alois Riegl would identify as the "haptic". Fuss's long daguerreotype exposures and direct-contact photograms depend on a fusion between a physical presence and the light-sensitive surface on which it makes its presence manifest. ${ }^{22}$ In an analysis of similarly grainy and ambiguous imagery in Atom Egoyan's cinema, Jacinto Lageira defines its haptic character as deriving from "a blend of grain and dot patterns of the images ... and also ... from the layers of material which signify in virtue of their depth, the transparency, and so on ... the pictorial treatment of these layers serves a double function in [Atom] Egoyan's films: it serves to reveal or to hide a story; and it veils or unveils an image."23 The optic mode of consumption imposes an emotional and physical distance from the subject that is destroyed by the haptic's intimate "at-handness". In the haptic character of Fuss's work, and that of other retro-avant-garde photographers, the eye does not scan the image for or become dazed by stupefying details, but it travels across the image as one's hand might traverse it if one's eyes were closed. When Fuss admits that these images carry "much less information" than typical photographs, he notes that the result is "much more intimacy". ${ }^{24}$

In her analysis of "haptic cinema", Laura Marks notes that its images "encourag[e] the viewer to engage with the image through memory", and by working from that interior response, "haptic images can give the impression of seeing for the first time, gradually discovering what is in the image rather than coming to an image already knowing what it is." ${ }^{25}$ This quality of feeling as if our sense of sight is new and that images are being formed before our eyes comes about partially because of the material properties and processes of these images. In the mid-1980s, for example, Susan Derges made images of the Chladni effect by vibrating powdered carborundum on photographic paper in order to make a photogram of the resulting patterns. The creation of these images, resulting from a material process, was perceived and felt by the viewer, which reveals formerly invisible material forces. In the 18th century, Ernst Chladni was attempting to find a grammar of music through these physical properties. Adorno suggests that the "all truth of artworks ... iridescently discloses itself in the catastrophic technological progress." 26

It is the context of the waning of traditional, indexical print photography that the work of Alison Rossiter (1953-) becomes most interesting. Her work is an exploration of the very ground on which photography's historical trajectory is written - the variants of classic photographic paper on which images have been printed. Attending to the ground on which a medium exists and the chemicals which bring images into being, Rossiter's work asserts something like the body of photography itself, the very material reality on which photography's transformative reality depends. After hunting down the remaining stock of now-unavailable classic photographic papers, Rossiter takes the developer and pours and controls its flow over the unexposed, but flawed, surfaces of these hallmark grounds. Her Eastman Kodak, Velvet Velux, Expiration date December 1926, (2014) is an example of how her images arise out of the imperfections and gradual degradation of these archaic papers. Its chance effects are a sign of the paper's life in storage and of the passing of time. Rossiter's work reveals this time-lapse effect in a manner reminiscent of Man Ray's Dust Breeding (1920/1967) photograph, which chronicled Marcel Duchamp's "work" on the Large Glass (1915-23). Duchamp's acceptance of the accumulation of dust on the surface of the work, fixing it into the final configuration of the piece, indicated the passage of time like the sand flowing in an hour glass. Non-intervention, the passive acceptance of the changing conditions without dictatorial human control, the embrace of chance, and even the

22 Alois Riegl first introduces the oppositional pair of haptic and optic in his Late Roman Art Industry of 1901; trans. Rolf Winkes Giorgio Bretschneider, 1985.

23 (Lageira 1996, p. 44).

24 (Fuss 2010, n.p.).

25 (Marks 2008, pp. 403-4).

26 (Adorno [1934] 1990, p. 61). 
agency/life of material things are all operational in Rossiter's historical archeology. ${ }^{27}$ It is not so much her use of chance effects as her excavation of the image's material origin that relates to mistical artistic concerns. This is expressed in the uniquely ambiguous visual character of Rossiter's images, forms one might call, following Chladni, "ur-images" — of the very birth of an image in material form and in sensual apprehension.

\section{Conclusions}

Our digital datascape is, on the one hand, simply an evolution of the modernist impulse to track and plot the physical world. However, because it does so through bits of information, unmooring its connection to the physical world in order to distribute images across technologies, it has the potential to become a denial of material reality. The artists under discussion here, though, foreground the material processes, presence, and origin of their aesthetic objects. By denying our desire for visual supremacy, they force a sensory adjustment and attunement using other bodily functions and associations. For Sobchack, the danger of electronic cinematic imagery is that it turns its back on the ethical ground of material reality. That ethical, material ground is still available for her in historical [print] photography and in the "subjective animation" of film-based cinema. ${ }^{28}$ It is the loosening of the image from its groundedness in the body, its unmooring from any anchoring referentiality, its free-floating signification that loosens its grip on our sensual presence in the world and thus also severs it from history. This homeless form of representation has the most profound implications for the shift from analogue to digital. The gradual independence of the image from its referent is a process that Adorno and Benjamin trace back to the invention of print photography. Noting how print photography "drove out of photographs the shy relation to the speechless subject that still reigned in daguerreotypes", these Frankfurt School philosophers gave an account of what was lost when adopting the new image-technology. Print photography thus replaced the intimacy of the long-exposure daguerreotypes with what Adorno called "photographic sovereignty". ${ }^{29}$ There is perhaps no better historical label to extend to new use in our present datascape than "photographic sovereignty". Our present life consists of swimming in a tepid bath of free-floating data-driven imagery, where Virilio's state of substitution reigns.

We are so enamored with our hyper-detailed field of digitized information-laden images that the works of these mistical artists may seem like so many ghosts in the machine. Our datascape has enacted a new form of visual orthodoxy. The fact that many of these works, especially the installations of Eliasson and architecture of Diller + Scofidio, but even the unique photographic prints of Fuss, Rossiter and Derges, do not reproduce well across our realm of "ubiquitous photographic" transmission should be embraced as a strength. These mistical artists and architects seem rather to demand Renee van de Wall's "tasten denken" (a groping form of thinking through the senses), a close phenomenological parallel to Merleau-Ponty's "palper du regard". In light of the contemporary demands placed on us for data-consumption and distribution, the mistical works discussed here offer a recovery of "uncertainty

27 Another fascinating exploration of historical forms of photography, although one that implements very recent digital technology to do so, is Thomas Ruff's photogram series and his imagery based on pornographic images (Nudes, ca. 2003-). In his Negative series (2014-), he scans 19th-century vernacular albumen prints, inverts the tonal values, and produces positive C-prints images of the inverted "negative" values in tones of blue. In Ruff's Photogram series (2013-), he sets up a virtual darkroom inside computer software, where simulated three-dimensional objects are exposed to light, moved, and manipulated to produce geometric and abstract virtual photograms. In all three of these series, his embrace of the mistical and obscure images that result is undertaken with a critical eye to the political implications embedded in this heritage. His is therefore a more conceptual approach than found in the other artists and architects discussed here. See Geoff Dyer, "Porn and the Shadow of Paradise: Thomas Ruff's Nudes," (Dyer 2012) for a summary of the Nudes series and Harry Thorne, "Thomas Ruff: Nature Morte," (Thorne 2015) for a discussion of his Negative series.

28 (Sobchack 2004, p. 154). She goes on the claim that electronic imagery creates, "space [that] becomes correlatively experienced as abstract, ungrounded, and flat-a site (or screen) for play and display rather than an invested situation in which action counts rather than computes" (p. 158).

29 (Adorno [1934/28] 1990, p. 48). 
and doubt" of the contingency of bodily knowledge, and of "slow, hesitant and uncertain" "palpating vision". ${ }^{30}$

The slickly produced spectacles that feed our visual appetites provide us with a fleeting fantasy of optical omnipotence and control. In a datascape set on visually recording and plotting everything, works that remain mysterious and ambiguous are far too rare and provide fleeting experiences for "disenchanted moderns who have grown disenchanted with modern disenchantment", in the words of Kosky. ${ }^{31}$ Rather than viewing and experiencing misty, foggy, and ambiguous forms and spaces as lacking information, where "blur is understood as loss", we can instead embrace Elizabeth Diller's notion that blur "can also be thought positively". ${ }^{32}$ The shadows, shrouds, and films of obfuscating mists found in these works elicit a bodily response to their materiality, one that foregrounds our continuity with space, our belongingness to it. It is a mistical version of Jane Bennet's "vibrant matter". If modernist philosophy is dependent on reifying the distinction between subject and object, of clarifying the particularities of difference, the vital materialist instead lingers at the recognition of mutuality of subject and object, at those moments "during which they find themselves fascinated by objects [and space], taking them as clues to the material vitality that they share with them." ${ }^{\prime 3}$

Funding: This research was partially supported through the Roger Williams University Foundation to Promote Scholarship and Teaching.

Conflicts of Interest: The author declares no conflict of interest.

\section{References}

Adorno, Theodor W. ; Translated by Thomas Y. Levin. 1990. The Curves of the Needle. October 55: 48-55. First published 1927/28. [CrossRef]

Adorno, Theodor W. ; Translated by Thomas Y. Levin. 1990. The Form of the Phonograph Record. October 55: 56-61. First published 1934. [CrossRef]

Adorno, Theodor W. 1997. Aesthetic Theory. Translated and Edited by Robert Hullot-Kentor. Minneapolis: The University of Minnesota Press.

Benjamin, Walter. 1992. The Work of Art in the Age of Mechanical Reproduction. In Art in Modern Culture: An Anthology of Critical Texts. Edited by Francis Frascina and Jonathan Harris. London: Phaidon Press Limited, pp. 297-307. First published 1936.

Bennet, Jane. 2010. Vibrant Matter: A Political Ecology of Things. Durham: Duke University Press.

Choi, Jung. 2014. Conceptual Laboratory of Depth: Olafur Eliasson's Your Atmospheric Colour Atlas. Sztuka i Dokumentacja 10: 61-66.

Diller, Elizabeth. 2002. Blur/Babble. In Blur: The Making of Nothing. New York: Harry Abrams, Originally published as 2001. Anything. Edited by Cynthia Davidson. Cambridge: MIT Press.

Dyer, Geoff. 2012. Porn and the Shadow of Paradise: Thomas Ruff's Nudes. The Guardian. March 2. Available online: https: / www.theguardian.com/artanddesign/2012/mar/02/porn-shadow-side-paradise-thomasruff (accessed on 8 November 2017).

Fuss, Adam. 2010. Video Interview for the Victoria and Albert Museum's Shadow Catchers. Available online: https:/ / vimeo.com/13149236 (accessed on 1 November 2017).

Kosky, Jeffrey L. 2013. Arts of Wonder: Enchanting Secularity—Walter DeMaria, Diller + Scofidio, James Turrell, Andy Goldsworthy. Chicago: University of Chicago Press.

Lageira, Jacinto. 1996. Scenario of the Untouchable Body. Public 13: 32-47.

Marks, Laura U. 2000. The Skin of the Film: Intercultural Cinema, Embodiment, and the Senses. Durham: Duke University Press.

30 (van de Wall 2008, p. 5). Van de Wall herself makes explicit the connection between her tasten denken and Merleau-Ponty's phenomenology (5).

1 (Kosky 2013, p. 176).

32 (Diller [2001] 2002, p. 133).

33 (Bennet 2010, p. 16). 
Marks, Laura U. 2008. Haptic Cinema. In Visual Sense: A Cultural Reader. Edited by Elizabeth Edwards and Kaushik Bhaumik. Brooklyn: Berg Pub., pp. 399-407.

Paterson, Mark. 2016. Architecture of Sensation: Affect, Motility and the Oculomotor. Body E Society 23: 3-35.

Rexer, Lyle. 2002. Photography's Antiquarian Avant-Garde: The New Wave in Old Processes. New York: Harry N. Abrams.

Sobchack, Vivian. 2004. Carnal Thoughts: Embodiment and Moving Image Culture. Berkeley: University of California Press.

Elizabeth, Ströker. 1965. Investigations in Philosophy of Space. Translated by Algis Mickunas. Athens: Ohio University Press.

Thompson, Nato, ed. 2012. Living as Form: Socially Engaged Art from 1991-2011. New York: Creative Book.

Thorne, Harry. 2015. Thomas Ruff: Nature Morte. Studio International. originally published 27 August 2015. Available online: http:/ /www.studiointernational.com/index.php/thomas-ruff-nature-morte-reiewgagosian-gallery-london-photography-negatives (accessed on 2 December 2017).

van de Wall, Renee. 2008. At the Edges of Vision. Farnham: Ashgate Publishing.

Virilio, Paul. 2000. The Information Bomb. Translated by Chris Turner. London: Verso. First published 1998.

Wilson, Luoise, and Paul Virilio. 1994. Interview with Paul Virilio. Cyberwar, God and Television: Interview with Paul Virilio. CTheory.org. Available online: http:/ / www.ctheory.net/articles.aspx?id=62 (accessed on 1 December 2018).

(C) 2019 by the author. Licensee MDPI, Basel, Switzerland. This article is an open access article distributed under the terms and conditions of the Creative Commons Attribution (CC BY) license (http://creativecommons.org/licenses/by/4.0/). 